\title{
Effects of Circuit Resistance Training with Crocus sativus Supplementation on Insulin and Estradiol Hormones Response
}

\author{
Ghanbari-Niaki A. ${ }^{1}$ PhD, Ardeshiri S. ${ }^{1}$ MSc, Aliakbari-Baydokhty M.* $M S c$, Saeidi A. ${ }^{1}$ MSc
}

*Physical Education Department, Physical Education \& Sport Sciences Faculty, University of Birjand, Birjand, Iran

${ }^{1}$ Exercise Physiology Department, Physical Education \& Sport Science Faculty, Mazandaran University, Babolsar, Iran

\begin{abstract}
Aims: During recent years, consumption of nutritional supplements has become popular in the athletes to enhance muscle power, function, and hypertrophy. Since the chemical supplements cause side-effects, many experts focus on the traditional medications. The aim of this study was to investigate Supplementation on the insulin and estradiol levels.

Materials \& Methods: In the semi-experimental study, 44 untrained healthy method in 2013. The samples were divided into four groups including "watermaximum repetition per station; 5 sessions a week). 500mg Crocus sativus were daily consumed two times in the morning immediately after the exercises. Blood sampling was done before and 48 hours after the last session. Data was analyzed by SPSS 20 software using one-way ANOVA, Bonferroni post-hoc, and dependent T tests.

Findings: There was a significant increase in the estradiol level in stigmaincreases in the plasma estradiol concentration in each stigma-exercise and style-exercise groups after the exercises $(\mathrm{p}<0.05)$. However, there was no significant difference between the mean of insulin concentrations in each group ( $\mathrm{p}>0.05)$.

Conclusion: Circular resistance exercises with Crocus sativus supplementation lead to no change in insulin concentration. Nevertheless, consumption of the stigma of Crocus sativus flower can empower the effects of the resistance exercises and enhance estradiol.

Keywords

Resistance Training [http://www.ncbi.nlm.nih.gov/mesh/68055070];

Estradiol [http://www.ncbi.nlm.nih.gov/mesh/68004958];

Insulin [http://www.ncbi.nlm.nih.gov/mesh/68007328];

Crocus [http://www.ncbi.nlm.nih.gov/mesh/68027622]
\end{abstract} the effects of short-term circular resistance exercises with Crocus sativus men were selected from the students of Mazandaran University using census exercise", "petal sweat-exercise", "style-exercise", and "stigma-exercise". 2week resistance exercises consisted of 12 stations (30 seconds with $40 \%$ of a exercise group than water-exercise group $(p=0.007)$. There were significant

\footnotetext{
* Corresponding Author

Tel: +985157332727

Fax: +985157332727

Address: NO 20, Chamran Street, Baydokht, Gonabad, Razavi Khorasan, Iran. Postal Code: 9694114439

aliakbaribidokhti@yahoo.com

Received: June 22, $2015 \quad$ Accepted: January 11, 2016 ePublished: March 5, 2016
} 
مقدمه

فعاليت ورزشى مقاومتى، سازگًارى كوتاممدت و طولانىمدتى را در

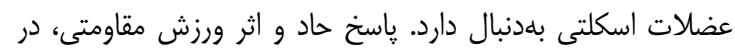

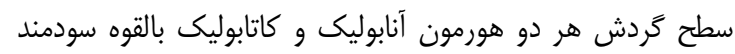

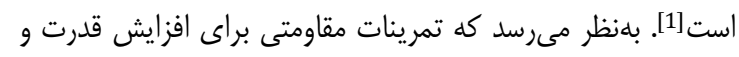

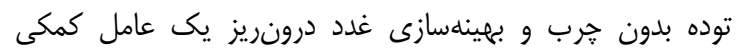

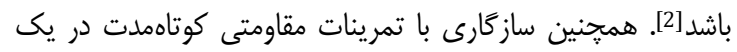

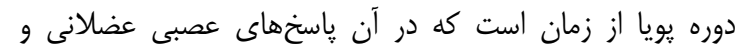

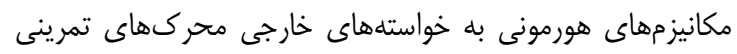
بلوجود مى آيد[3].

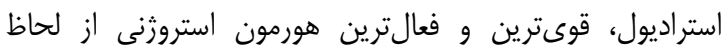
بيولوزيك است[4]. استراديول يك استروزن است. استروزنها در زنهاى سالم موجب رشد تكامل اندام جنسى، حفظ عملكرد طبيعى ئى

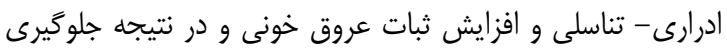

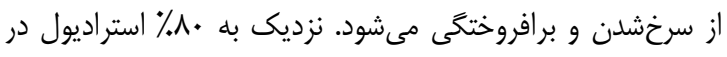

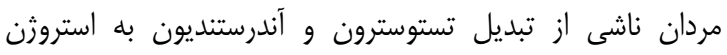

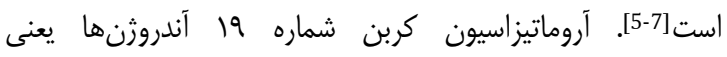

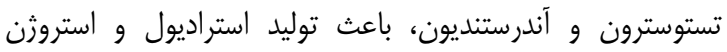

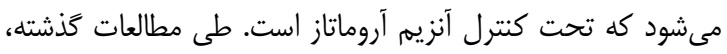

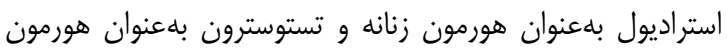
مردانه مورد توجه بودهاند. امروزه با شناسايى اعمال مهرم استروزن هونها در دستخاه تناسلى مردان، نقش اين هورمون در بارورى مردى مردان

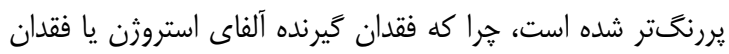

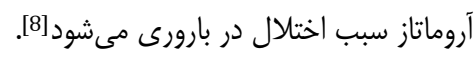

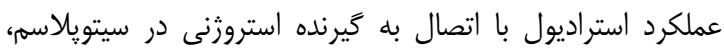

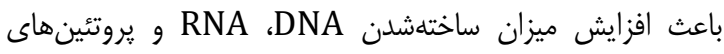

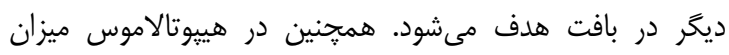

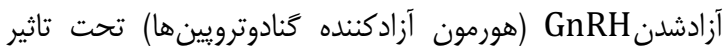
استروزن كاهش ييدا مى كند و در هييوفيز آزادشدن FSH (هورمون محرى فوليكول) و LH (هورمون لوتئينى كننده) كاهش مى ئيل ويابد. استراديول بلهنوان دارو در كمبود هورمون استروزن و بيمارىهاى

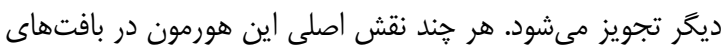

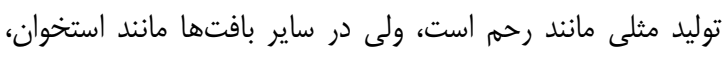

كبد، عروق خونى و مغز نيز تاثير دارد[6].

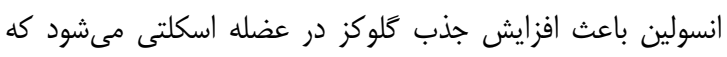

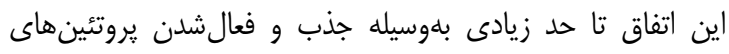

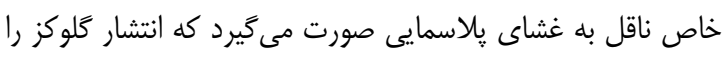

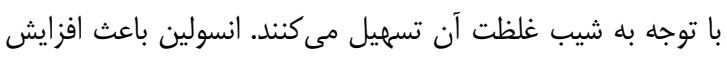
جريان خون فيزيولوزيك به عضله اسكلتى مىشود[9]. انسولين

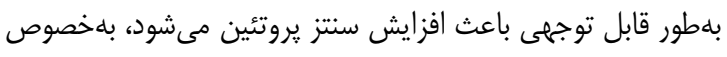

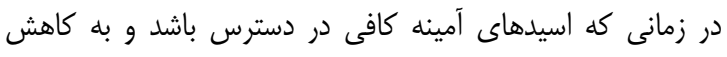
كاتابوليزم يروتئين منجر مىشود. تغييرات غلظت انسولين سرم

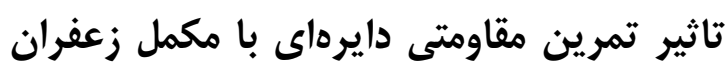
بر ياسخ هورمونهاى انسولين و استر اديول

عباس قنبرى نياكى PhD

كروه فيزيولوزى ورزشى، دانشكده تربي نبيت بدنى و علوم ورزشى، دانشكاه مازندران، بابلسر، ايران

صادق اردشيرى MSc

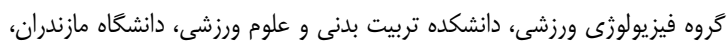
بابلسر، ايران

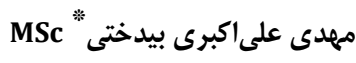

كروه تربيت بدنى، دانشكده تربيت بدنى و وعلوم بيدى ورزشى، دانشعاه بيرجند، بيرجند،

ايران

ايوب سعيدى MSc

كروه فيزيولوزى ورزشى، دانشكده تربيت بدنى و علوم ورزشى، دانشكاه مازندران، بابلسر، ايران

جكيده

اهداف: طى سالهاى اخير استفاده از مكملهاى غذايى براى بهبود

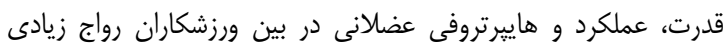
يافته است. با توجه به اثرات جانبى مكمل هایى شيميايى، توجه بسيارى از از مختصصان تغذيه بلهوى داروهاى سنتى معطوف شده است. هدف إنى

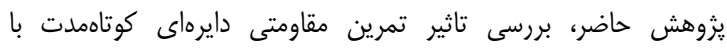

مكملسازى زعفران بر سطوح هورمونهاى استراديول و انسولين بود.

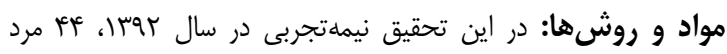

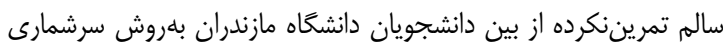

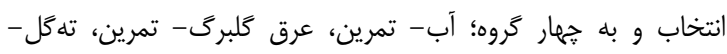

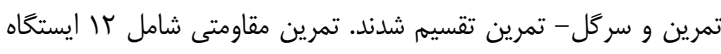

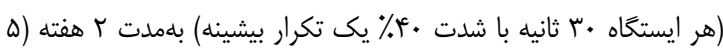

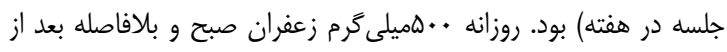

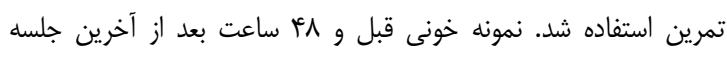

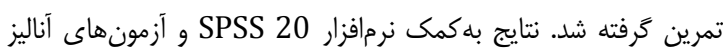

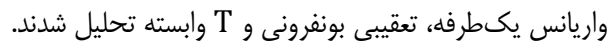

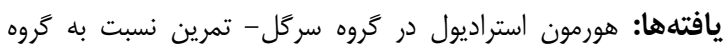

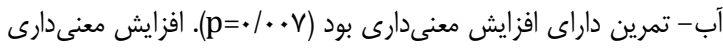

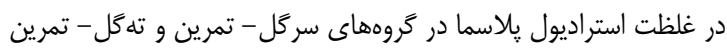

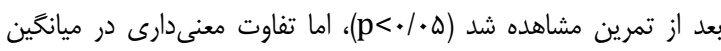

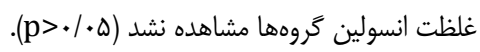
نتيجهَّيرى: تمرين مقاومتى دايرهاى همراه با مكملدهیى زعفران

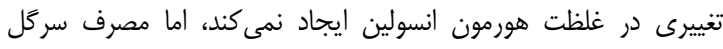

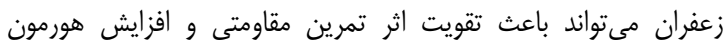
استر اديول شود. كليدوازهها: تمرين مقاومتى دايرهاى، استراديول، انسولين، زعفران

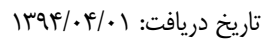

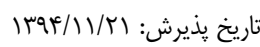
"نويسنده مسئول: aliakbaribidokhti@yahoo.com 


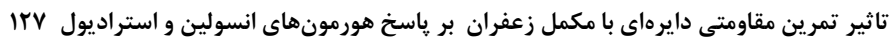

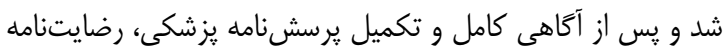

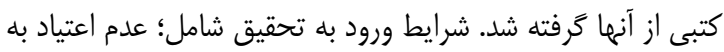
مواد مخدر و الكل، نداشتن سابقه فعاليت ورزشى منظم حدى حداقل

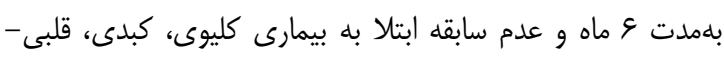

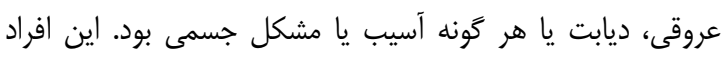

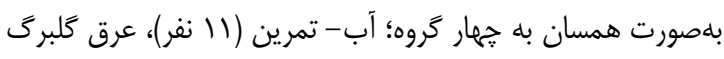

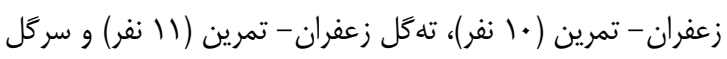

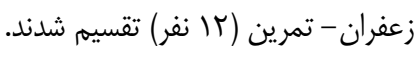

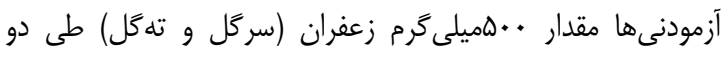

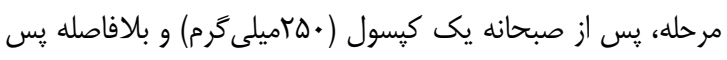

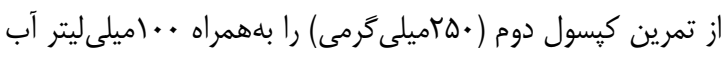

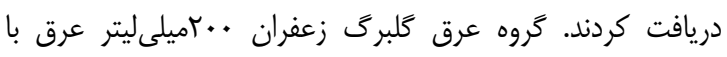

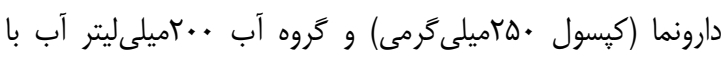

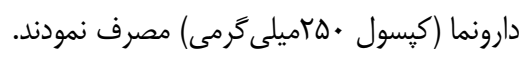
دستورالعمل تمرين به اين صورت بود كه قبل از انجامل إنمام تمرين

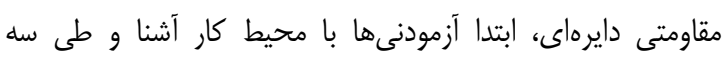
جلسه مجزا براى تعيين 1RM (يك تكرار بيشينه) حركات مورد إنى نظر به محل تمرين مراجعه نمودند. طى اين سه جلس جلسه مقادير 1RM حركات اسكوات، يرس سينه هالتر، ساق ڤا دستخاه، سرشانه

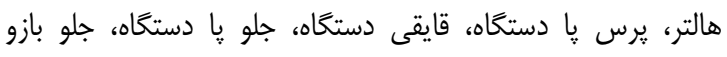

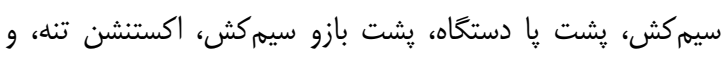

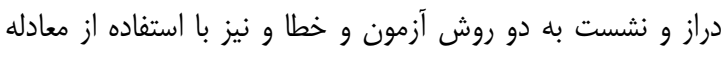

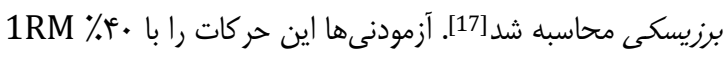
ميانگين با سرعت متوسط بهمدت دو هفته (ه جلسه در هفته) انجام

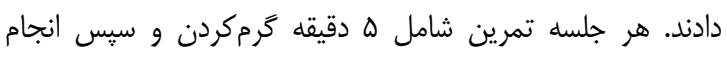

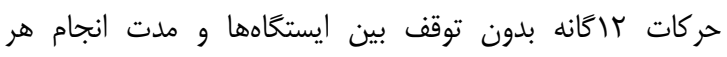

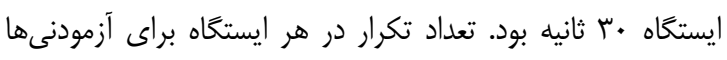
ثبت شد. دو جلسه اول يك نوبت تمرين انجام شد. از جلسه سوم

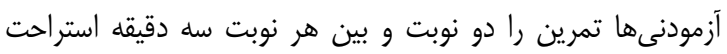
فعال انجام دادند.

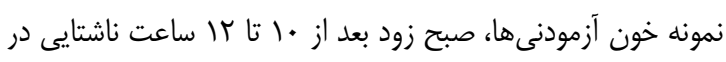

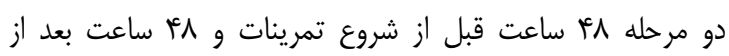

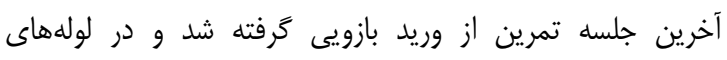
آزمايش حاوى EDTA (اتيلن دى آمين تترا استيكاسيد) ريخته شد. نمونهاى خونى با سرعت . ..." دور در دقيقه بلهمدت .

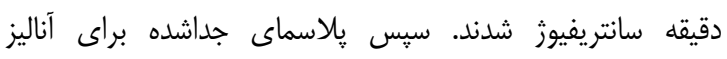

هورمونهاى استراديول و انسولين مورد استفاده قرار كرفت. Elecsys 2010 ( براى اندازهيرى هورمونها از دستخاه HITACHI Roche

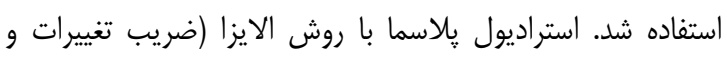

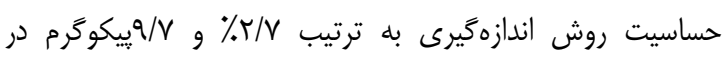
ميلىليتر) با استفاده از كيت تشخيص استراديول انسان (شركت بت تركيرك
موازى با تغييرات قند خون است و اين پاسخ زمانى افزايش مىيابد

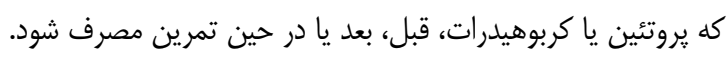

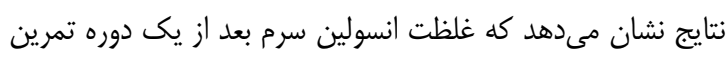

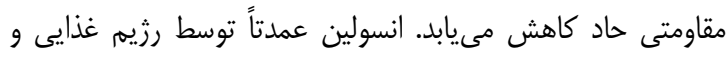

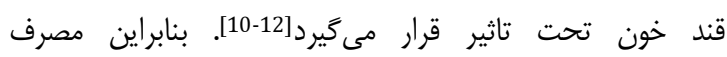

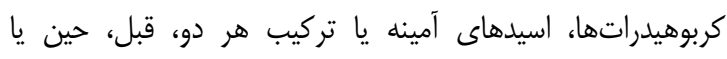
بلافاصله يس از تمرين مقاومتى براى بهحداكثررساندن اثرات

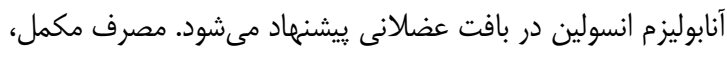
قبل يا حين تمرين مقاومتى بلويثه براى بلهحاكثررساندن سنتز

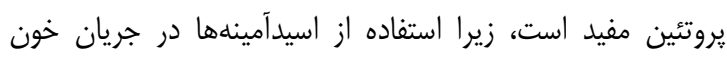

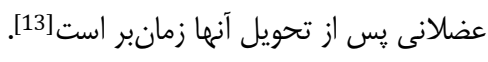

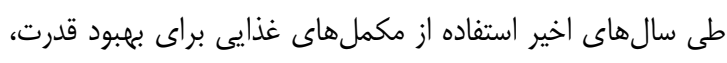

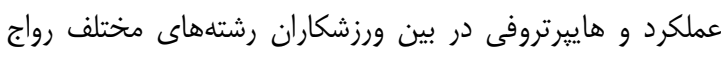

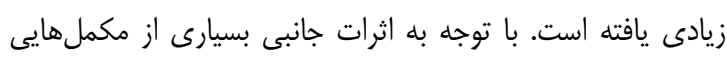
كه بهصورت شيميايى تهيه و توليد مى ياقشود، توجه بسيارى از

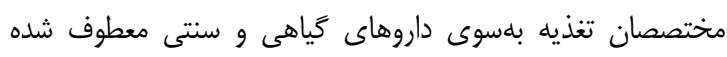

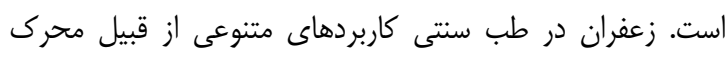

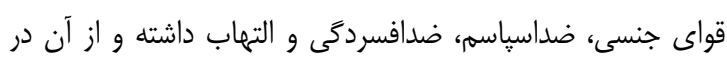

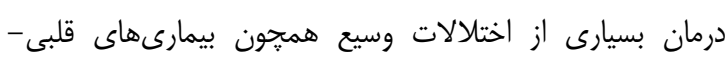

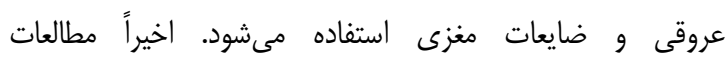
فارماكولوزى بر فعاليت زيستى عصارههاى گياهى و خوات خواص آنتىاكسيدانى آن متمركز شده است. عصاره زعفران شامل تركيبات

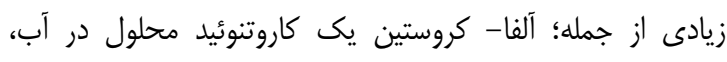
كروسين، دى زكروسين، ترى كروسين، وييكروكروسين و و سافرنال

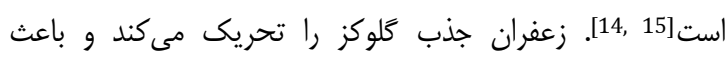
افزايش حساسيت به انسولين در سلول عضله اسكلتى از طريق

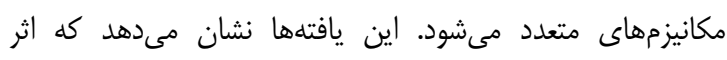
كاهنده قند خون زعفران مربوط به سوختوساز فعاليت زعفران در عضله اسكلتى است [16].

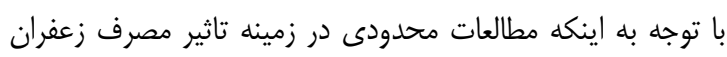

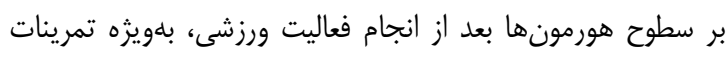
مقاومتى انجام شده است و از طرفى مطالعاتى در زمينه تاثير

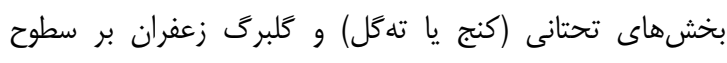

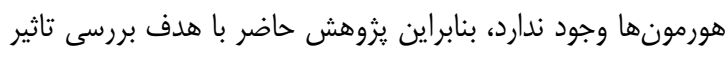

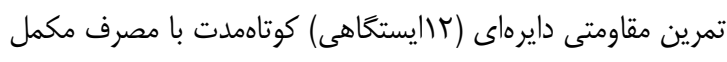
زعفران بر سطوح هورمونهاى استراديول و انسولين انجام شد.

\section{مواد و روشها}

تحقيق حاضر در قالب طرح نيمهتجربى در سال זوسا در بين

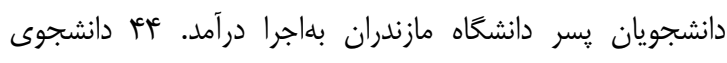

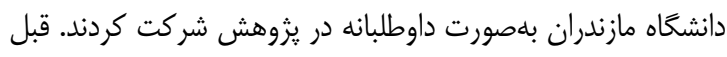

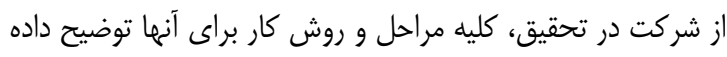




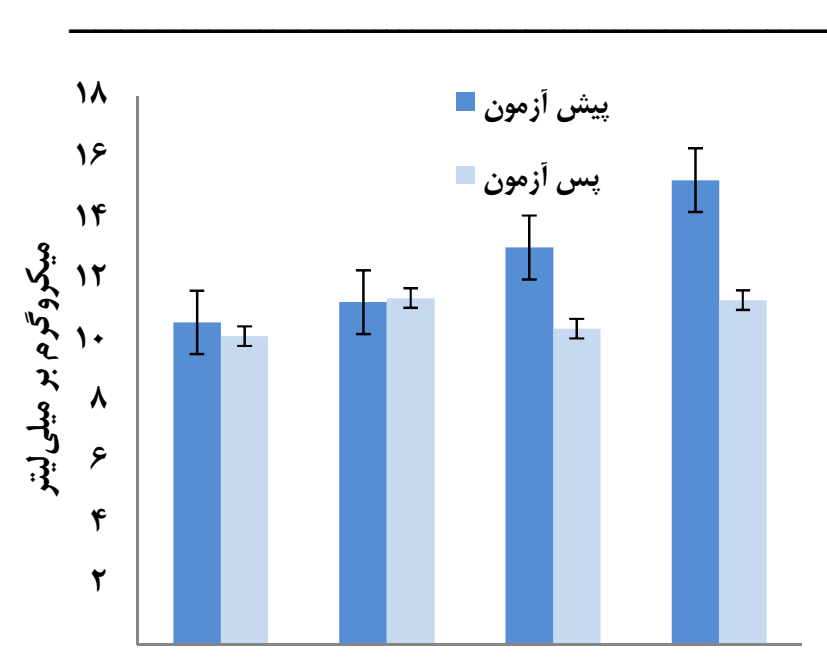

سركل - تمرين ته كَل-تمرين عرق- تمرين آب-تمرين

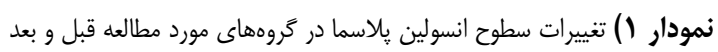

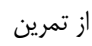

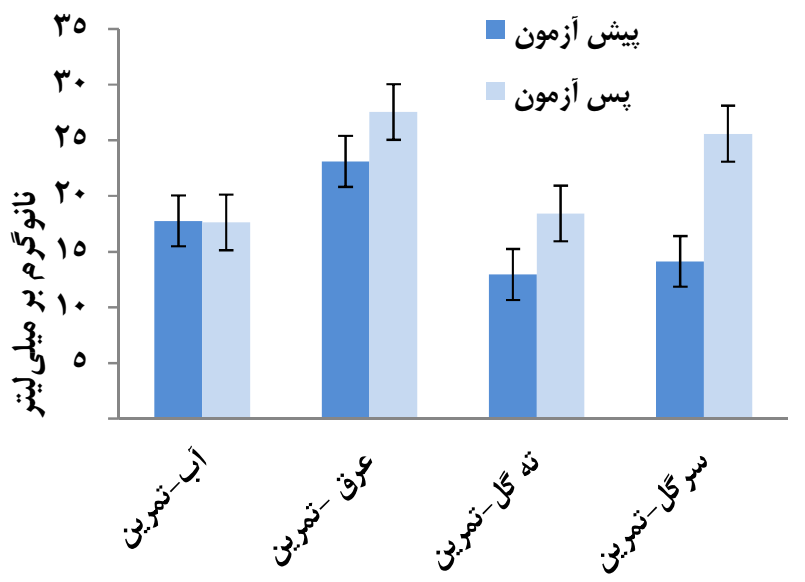

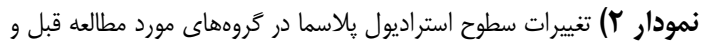

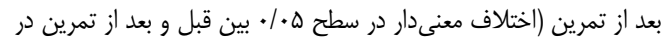

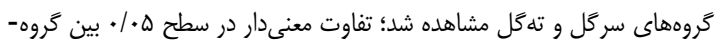

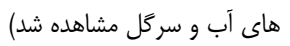

\section{بحث}

در يزوهش حاضر ڤِاسخ هورمونهاى انسولين و استراديول پِاسما

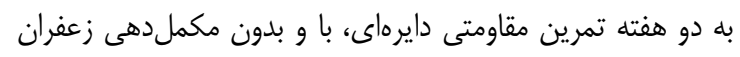

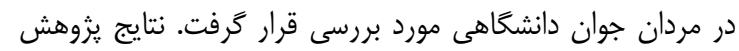

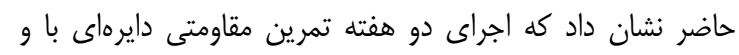

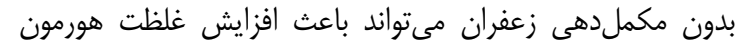

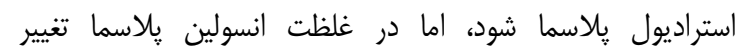

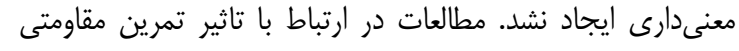

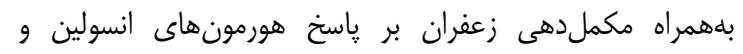
استراديول پلاسما بسيار اندى است.

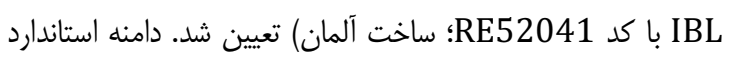

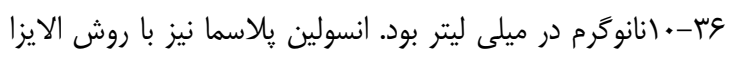

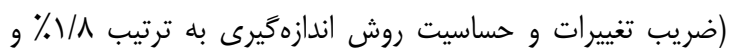

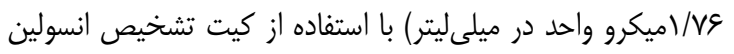

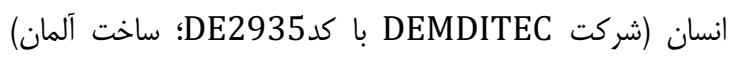

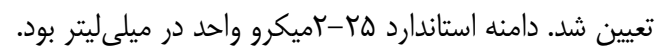

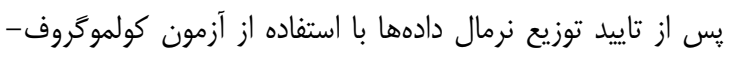

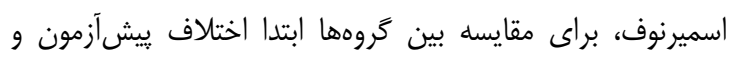

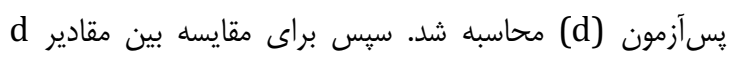

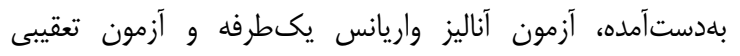

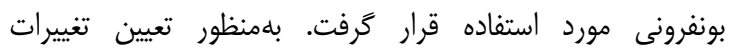

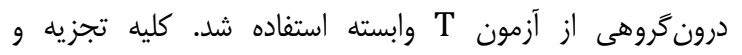
تحليلها با استفاده از نرمافزار آمارى 20 SPSS صورت كرو كرفت.

يافتهها ميانغين آمارى مشخصات دموكرافيى آزمودنىها در هر كروه در

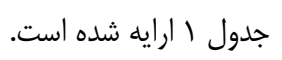

\begin{tabular}{|c|c|c|c|}
\hline سرَّل- تمرين & ته & عرق - تمرين & آب- تمرين \\
\hline$r / / \Delta \cdot \pm 1 / q r$ & $r / / \Lambda \pm I / V r$ & $\Gamma r / \cdot \cdot \pm T / \Gamma_{\Delta}$ & سن (سال) \\
\hline$|V Q / q T \pm \Delta / \Gamma|$ & $\mid V \Delta / r q \pm \bar{Y} / \varphi$ & $\left|V_{\Delta} / 1 \cdot \pm \varepsilon\right| \cdot \Lambda$ & قد (سانتىمتر) \\
\hline 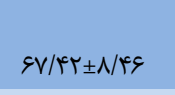 & $g V / r \xi \pm N / r)$ & $V N / 1 \cdot \pm 1 \cdot / 01$ & 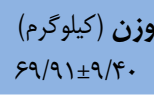 \\
\hline$r \mid / V \Delta \pm 1 / ৭ \&$ & $r I / \Lambda r \pm r / \varepsilon$. & كيلوكرم بر مترمربع/ & 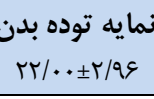 \\
\hline
\end{tabular}

بين گروههاى مورد مطالعه، در سطوح هورمون انسولين تغيير

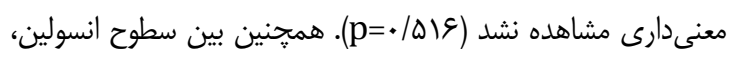

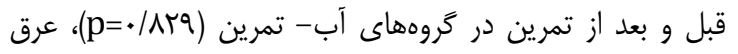

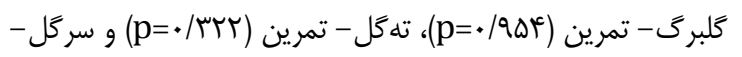

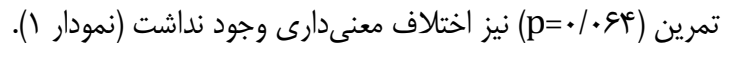

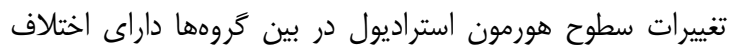

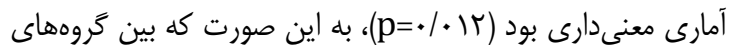

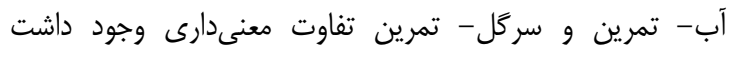
(p=•/.•V)

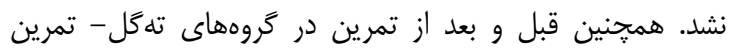

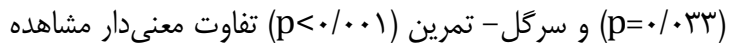

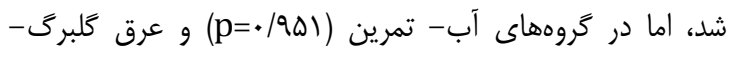

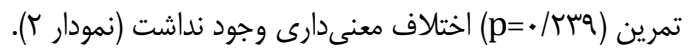




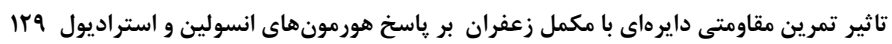

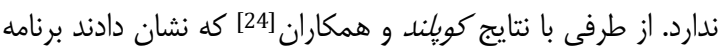
تمرينى استقامتى و مقاومتى در ميزان استراديول تغييراتى ايجاد

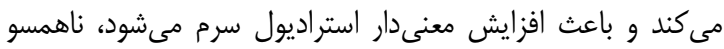

است.

استراديول باعث بهبود جريان خون عروق كرونرى مىشود[5]. 25.].

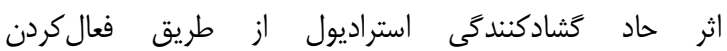

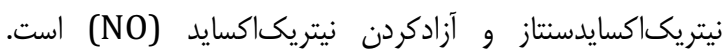
ييشنهاد شده است كه اين مكانيزم از طريق فعالشدن كيرنده آلفاى

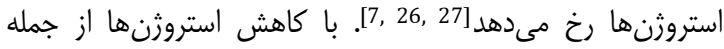

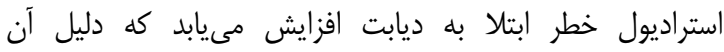

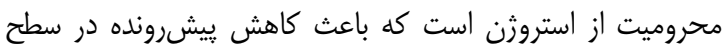
انسولين و تحريك كلوكز و در نتيجه افزايش مقاومت به انسولين و كاهش حساسيت به انسولين مىشود. بنابراين قابل تصور است كه كه كاهش سوختوساز كلوكز بلن تا حدودى مربوط به محروميت از استروزنها مخصوصاً استراديول است. در خصوص تمرين مقاومتى دايرهاى همراه با مكملدهى زعفى زعفران

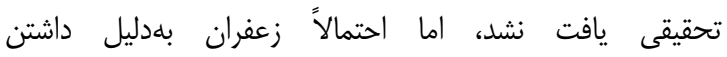

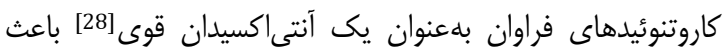

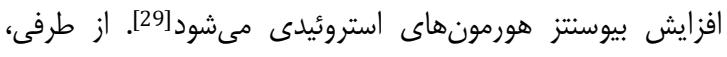
نقش هورمون استراديول در سيسته ايمنى بلخخوبى شناخته شده

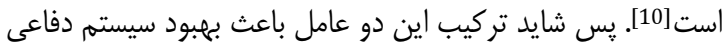

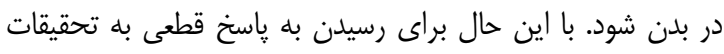
بيشترى نياز است.

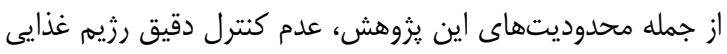

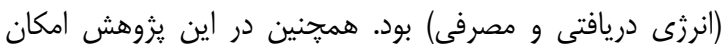

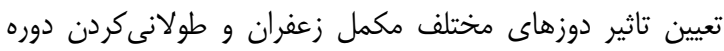

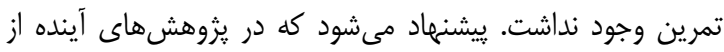

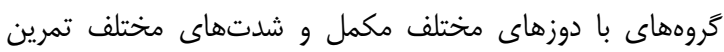
مقاومتى در دورههاى طولانىتر استفاده شود.

\section{نتيجه كَيرى}

تمرين مقاومتى دايرهاى همراه با مكمل زعفران تغييرى در ميانگين غلظت هورمون انسولين ايجاد نمى كند، اما مصرف مكمل سرگل زعفران مىتواند باعث تقويت اثر تمرين مقاومتى و افزايش هورمون

استراديول شود.

تشكر و قدردانى: در پايان از تمامى كسانى كه ما را در انجام

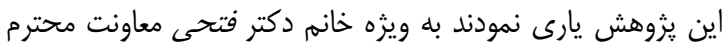
يزوهشى دانشكده تربيت بدنى و علوم ورزشى دانشكاه مازندران تقدير و سياسكزارى مىنماييم.

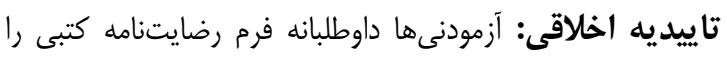

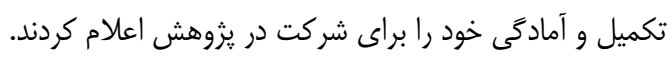

تمرينات مقاومتى باعث پاسخ حاد هورمونى مى شود. باسخ حاد

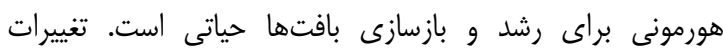

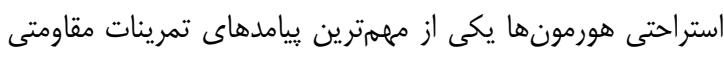

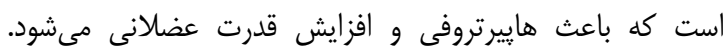

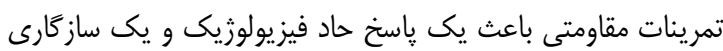

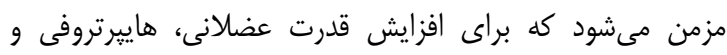

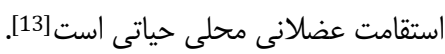

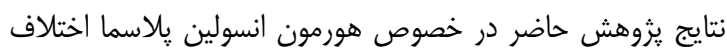

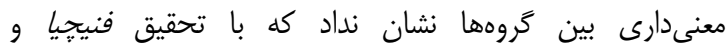

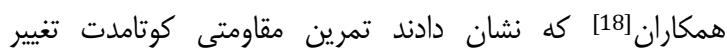

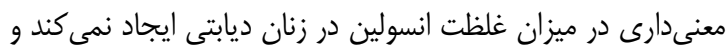

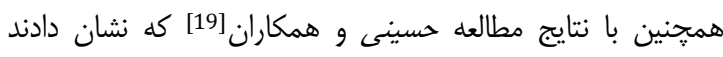

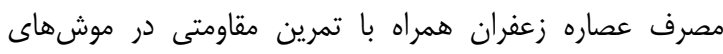

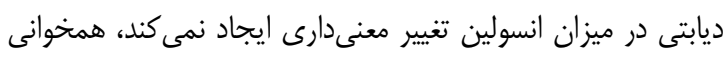

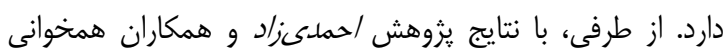

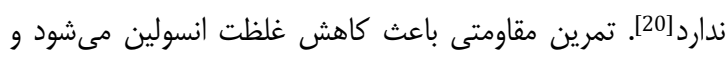

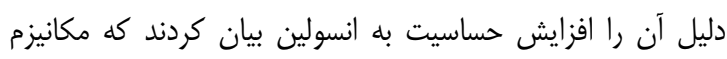

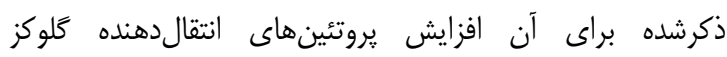
(GLUT4)

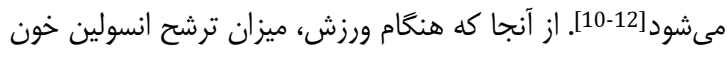

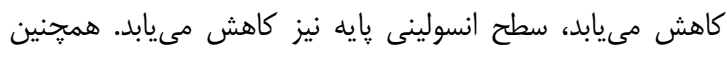

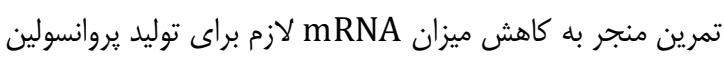

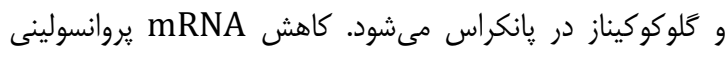

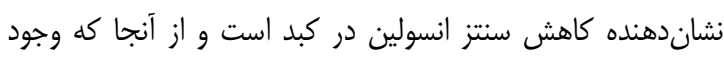

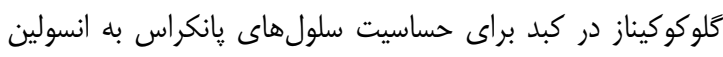
ضرورى است، بنابراين كاهش ميزان mRNA كلوكوكيناز ممكن

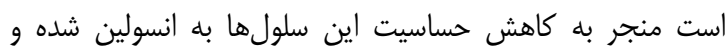

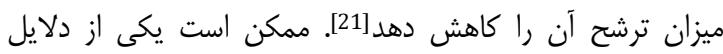

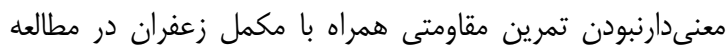

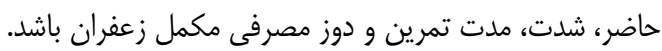

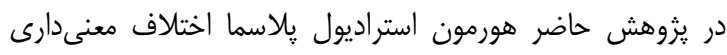

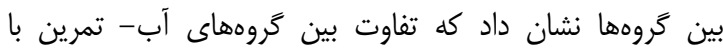

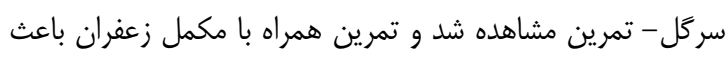

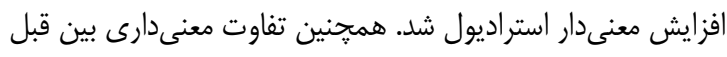

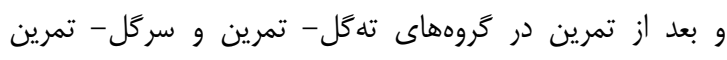

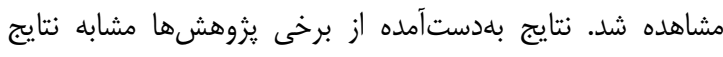

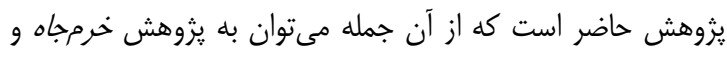

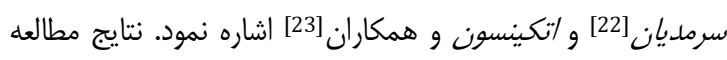

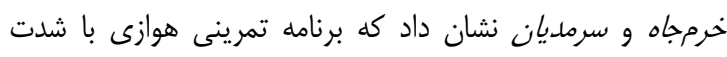
نهD-VD

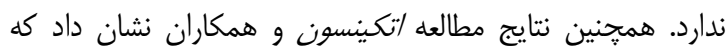
برنامه تمرينى با شدت متوسط تاثير معنىدارى بر استراديول سرم 
Umbria). Food Chem. 2014;143:446-51.

15- Razavi BM, Imenshahidi M, Abnous K, Hosseinzadeh M. Cardiovascular effects of saffron and its active constituents: A review article. Saffron Agron Technol. 2014;1(2):3-13. [Persian]

16- Kang C, Lee H, Jung ES, Seyedian R, Jo M, Kim J, et al. Saffron (Crocus sativus L.) increases glucose uptake and insulin sensitivity in muscle cells via multipathway mechanisms. Food Chem. 2012;135(4):2350-8.

17- Ghanbari-Niaki A, Saeidi A, Aliakbari-Beydokhti, M, Ardeshiri S, Kolahdouzi S, Chaichi MJ, et al. Effects of Circuit Resistance Training with Crocus Sativus (Saffron) Supplementation on Plasma Viscosity and Fibrinogen. Ann Appl Sport Sci. 2015;3(2):1-10.

18- Fenicchia LM, Kanaley JA, Azevedo JL, Miller CS, Weinstock RS, Carhart RL, et al. Influence of resistance exercise training on glucose control in women with type 2 diabetes. Metabo. 2004;53(3):284-9.

19- Hosseini S, Nikbakht H, Azarbayjani MA. The effect of aqua extract of saffron with resistance training on glycemic indexes of streptozotocin induced diabetic rats. Armaghan Danesh. 2013;18(4):284-94. [Persian]

20- Ahmadizad S, Khodamoradi A, Ebrahim K, Hedayati M. Effects of resistance exercise intensity on adipokines and insulin resistance index. Iran J Endocrinol Metab. 2010;12(4):427-34. [Persian]

21- Yavari A, Nagaphipour F, Asgarzadeh AA, Niafar M, Mobseri M, Nikokhoslat S. Effect of aerobic exercise, resistance training or combined training on glycemic control and cardiovascular risk factors in patients with type 2 diabetes mellitus. J Tabriz Univ Med Sci. 2011;33(4):82-91. [Persian]

22- Khoram jah M, Sarmadiyn M. Effects 10 weeks of aerobic training on serum levels of estradiol and percent body fat in sedentary postmenopausal overweight women. Iraan J Breast Dis. 2015;8(2):35-43. [Persian]

23- Atkinson C, Lampe JW, Tworoger SS, Ulrich CM, Bowen D, Irwin ML, et al. Effects of a moderate intensity exercise intervention on estrogen metabolism in postmenopausal women. Cancer Epidemiol Biomarkers Prev. 2004;13(5):868-74.

24- Copeland JL, Consitt LA, Tremblay MS. Hormonal responses to endurance and resistance exercise in females aged 19-69 years. J Gerontol A Biol Sci Med Sci. 2002;57(4):B158-65.

25- Collins P, Rosano GM, Sarrel PM, Ulrich L, Adamopoulos S, Beale CM, et al. $17 \beta$-Estradiol attenuates acetylcholine-induced coronary arterial constriction in women but not men with coronary heart disease. Circulation. 1995;92(1):24-30.

26- Bjornstrom L, Sjoberg M. Mechanisms of estrogen receptor signaling: Convergence of genomic and nongenomic actions on target genes. Mol Endocrinol. 2005;19(4):833-42.

27- Mendelsohn ME. Genomic and nongenomic effects of estrogen in the vasculature. Am J Cardiol. 2002;90(1):F34.

28- Melnyk JP, Wang S, Marcone MF. Chemical and biological properties of the world's most expensive spice: Saffron. Food Res Inte. 2010;43(8):1981-9.

29- Modaresi M, Messripour M, Asadi Marghmaleki M, Hamadanian M. Effect of saffron (Crocus sativus) extract on level of FSH, LH and testosterone in mice. J Zanjan Univ Med Sci. 2008;16(63):11-8. [Persian]

$$
\text { منابع مالى منافع: تعارض منافعى وجود ندارد. }
$$

1- Fry AC, Lohnes CA. Acute testosterone and cortisol responses to high power resistance exercise. Fiziol Cheloveka. 2010;36(4):102-6.

2- Bosco C, Colli R, Bonomi R, von Duvillard SP, Viru A. Monitoring strength training: Neuromuscular and hormonal profile. Med Sci Sports Exerc. 2000;32(1):2028.

3- Kraemer WJ, Volek JS, Bush JA, Putukian M, Sebastianelli WJ. Hormonal responses to consecutive days of heavy-resistance exercise with or without nutritional supplementation. J Appl Physiol. 1998;85(4):1544-55.

4- Chandler TJ, Brown LE. Conditioning for strength and human performance. Philadelphia Lippincott: Williams \& Wilkins; 2008.

5- Gulliver LSM. Estradiol synthesis and metabolism and risk of ovarian cancer in older women taking prescribed or plant-derived estrogen supplementation. J Steroids Horm Sci. 2013;12:1-5.

6- Fragala MS, Kraemer WJ, Denegar CR., Maresh CM, Mastro AM, Volek, JS. Neuroendocrine-immune interactions and responses to exercise. Sports Med. 2011;41(8):621-39.

7- Vitale C, Mendelsohn ME, Rosano GM. Gender differences in the cardiovascular effect of sex hormones. Nat Rev Cardiol. 2009;6(8):532-42.

8- Jafarian A, Akhondi MM, Pezhhan N, Sadeghi MR, Zarnani AH, Salehkhou S. Stimulatory effects of Estradiol and $\mathrm{FSH}$ on the restoration of spermatogenesis in azoospermic mice. J Reprod Infertil. 2009;9(4):317-24. [Persian]

9- Treebak JT, Pehmoller C, Kristensen JM, Kjobsted R, Birk JB, Schjerling $P$, et al. Acute exercise and physiological insulin induce distinct phosphorylation signatures on TBC1D1 and TBC1D4 proteins in human skeletal muscle. J Physiol. 2014;592(2):351-75.

10- Kraemer WJ, Solomon-Hill G, Volk BM, Kupchak BR., Looney DP, Dunn-Lewis C, et al. The effects of soy and whey protein supplementation on acute hormonal responses to resistance exercise in men. J Am Coll Nutr. 2013;32(1):66-74.

11- Reynolds TH, Supiano MA, Dengel DR. Regional differences in glucose clearance: effects of insulin and resistance training on arm and leg glucose clearance in older hypertensive individuals. J Appl Physiol. 2007;102(3):985-91.

12- Maiorana A, O'Driscoll G, Goodman C, Taylor R, Green D. Combined aerobic and resistance exercise improves glycemic control and fitness in type 2 diabetes. Diabetes Res Clin Pract. 2002;56(2):115-23.

13- Kraemer WJ, Ratamess NA. Hormonal responses and adaptations to resistance exercise and training. Sports Med. 2005;35(4):339-61.

14- Cossignani L, Urbani E, Simonetti MS, Maurizi A, Chiesi C, Blasi F. Characterisation of secondary metabolites in saffron from central Italy (Cascia, 